\title{
Synthesis of Polyhydroxyalkanoates from Oleic Acid by Cupriavidus necator B-10646
}

\author{
Natalia O. Zhila, ${ }^{a, b *}$, Galina S. Kalacheva ${ }^{a}$, \\ Evgeniy G. Kiselev ${ }^{\mathrm{a}, \mathrm{b}}$ and Tatiana G. Volova ${ }^{\mathrm{a}, \mathrm{b}}$ \\ anstitute of Biophysics SB RAS \\ FRC "Krasnoyarsk Science Center SB RAS" \\ Krasnoyarsk, Russian Federation \\ ${ }^{b}$ Siberian Federal University \\ Krasnoyarsk, Russian Federation
}

Received 14.11.2019, received in revised form 19.02.2020, accepted 24.03.2020, published online 22.05.2020

\begin{abstract}
Polyhydroxyalkanoates (PHAs) are polymers of hydroxy derived fatty acids synthesized by various organisms. These polymers can be effectively used as a biocompatible and biodegradable alternative to the chemically synthesized plastic. PHA cost, however, still limits the increase in PHA production. One of the ways to reduce PHA cost is to use inexpensive carbon sources such as fatty acids. The aim of this work was to study the effect of various concentrations of oleic acid (5-50 g/L) on the growth of the Cupriavidus necator B-10646 bacterium, polymer synthesis and properties. Cells were grown for $48 \mathrm{~h}$ in Schlegel mineral medium at $30^{\circ} \mathrm{C}$ and $200 \mathrm{rpm}$ on an incubator shaker. The content and the composition of the polymer were determined by chromatography of fatty acid methyl esters using a chromatographymass spectrometer. The molecular weight distribution of the polymer was determined using gel permeation chromatography. Thermal analysis was performed using a differential scanning calorimeter. The maximum yield of biomass $(6.4-6.7 \mathrm{~g} / \mathrm{L})$ and the highest polymer content (64$71 \%$ of the weight of dry biomass) were obtained from $10-20 \mathrm{~g} / \mathrm{L}$ of oleic acid after 48 hours of cultivation. In addition to 3-hydroxybutyrate, which is the dominant monomer (more than 98 mol.\%), 3-hydroxyvalerate (0.7-1.7 mol.\%) and 3-hydroxyhexanoate (0.1-0.4 mol.\%) were identified in the polymer synthesized by the bacterium. As the concentration of oleic acid was increased, both the weight average and the number average molecular weights decreased (from 803 to $381 \mathrm{kDa}$ and from 292 to $94 \mathrm{kDa}$, respectively) but polydispersity of the polymers increased (from 2.8 to 4.1). The results obtained in the present study provide the basis for the next stage of scaling up the process of PHA synthesis from oleic acid.
\end{abstract}

(C) Siberian Federal University. All rights reserved

This work is licensed under a Creative Commons Attribution-NonCommercial 4.0 International License (CC BY-NC 4.0).

* Corresponding author E-mail address: nzhila@mail.ru

ORCID: 0000-0002-6256-0025 (Zhila N.); 0000-0003-4472-7087 (Kiselev E.); 0000-0001-9392-156X (Volova T.) 
Keywords: Cupriavidus necator, polyhydroxyalkanoates, oleic acid, molecular weight.

Citation: Zhila N.O., Kalacheva G.S., Kiselev E.G., Volova T.G. Synthesis of polyhydroxyalkanoates from oleic acid by Cupriavidus necator B-10646. J. Sib. Fed. Univ. Biol., 2020, 13(2), 208-217. DOI: 10.17516/1997-1389-0321

\title{
Синтез полигидроксиалканоатов бактериями Cupriavidus necator B-10646 при росте
}

\section{на олеиновой кислоте}

\author{
Н.О. Жила ${ }^{\text {a, }}$, Г.С. Калачева ${ }^{a}$, \\ Е.Г. Киселев ${ }^{\mathbf{a}, \tilde{0}}$, Т.Г. Волова ${ }^{\mathrm{a}, \boldsymbol{\sigma}}$ \\ ${ }^{a}$ Институт биофизики СО РАН \\ ФИЦ «Красноярский научный центр СО РАН» \\ Российская Федераиия, Красноярск \\ ${ }^{6}$ Сибирский федеральный университет \\ Российская Федераиия, Красноярск
}

\begin{abstract}
Аннотация. Полигидроксиалканоаты - полимеры гидроксипроизводных жирных кислот, синтезируемые различными микроорганизмами, могут эффективно использоваться в качестве биоразрушаемой и биосовместимой альтернативы пластику, полученному путем химического синтеза. Однако стоимость ПГА по-прежнему ограничивает их производство. Одним из подходов снижения стоимости ПГА является использование недорогих углеродных источников, например таких, как жирные кислоты. Целью данной работы было исследование влияния различных концентраций олеиновой кислоты (5-50 г/л) на рост бактерий Cupriavidus necator B-10646, синтез полимера и его характеристики. Бактерии выращивали в течение 48 ч в минеральной среде Шлегеля в термостатируемом шейкере-инкубаторе при $30{ }^{\circ} \mathrm{C}$ и 200 об/мин. Содержание и состав полимера определяли хроматографией метиловых эфиров жирных кислот на газовом хромато-масс-спектрометре, молекулярномассовое распределение полимера - с использованием гельпроникающей хроматографии. Термический анализ проводили с помощью дифференциально-сканирующего калориметра. Максимальная концентрация биомассы (6,4-6,7 г/л) и содержание полимера (64-71% от веса сухой биомассы) получены при концентрациях олеиновой кислоты в среде 10-20 г/л за 48 ч культивирования. В составе полимера, синтезируемого бактериями, помимо 3-гидроксибутирата, являющегося доминирующим мономером (более 98 мол. \%), идентифицированы включения 3-гидроксивалерата (0,7-1,7 мол. \%) и 3-гидроксигексаноата (0,1-0,4 мол. \%). Показано, что с увеличением концентрации олеиновой кислоты происходило снижение как средневесовой (с 803 до 381 кДа), так и среднечисловой (с 292 до 94 кДа) молекулярной массы на фоне увеличения полидисперсности (с 2,8 до 4,1). Полученные результаты служат основой для последующего этапа масштабирования технологии синтеза ПГА из олеиновой кислоты.
\end{abstract}


Ключевые слова: Cupriavidus necator, полигидроксиалканоаты, олеиновая кислота, молекулярная масса.

Цитирование: Жила, Н.О. Синтез полигидроксиалканоатов бактериями Cupriavidus necator B-10646 при росте на олеиновой кислоте / Н.О. Жила, Г.С. Калачева, Е.Г. Киселев, Т.Г. Волова // Журн. Сиб. федер. ун-та. Биология, 2020. 13(2). C. 208-217. DOI: 10.17516/1997-1389-0321

\section{Введение}

Полигидроксиалканоаты (ПГА) считают хорошей заменой обычным пластикам. ПГА синтезируются микроорганизмами и могут разрушаться в аэробных условиях до воды и углекислого газа, до метана - в анаэробных условиях. Механические, химические и термические свойства ПГА могут регулироваться модифицированием состава и содержания мономеров. Однако широкому использованию ПГА препятствует их высокая цена по сравнению с химически синтезированными полимерами (Lee, Choi, 1998). С экономической точки зрения для коммерциализации продукции ПГА очень важно разработать новый процесс с низкой стоимостью и слабым загрязнением при выделении полимера из бактериальных клеток (Chen et al., 2001). Показано, что около 40 \% от цены поли(3гидроксибутирата) (П(ЗГБ)) приходится на используемый субстрат. Следовательно, для снижения высокой продукционной стоимости П(ЗГБ) необходимо применение более дешевых углеродных субстратов (Kim, 2000). В этой связи растительные масла (пальмовое, соевое, подсолнечное и др.), а также жирные кислоты (олеиновая, пальмитиновая, стеариновая и др.) могут быть использованы как для повышения продуктивности и урожая полимера, так и в качестве дешевых источников углерода (Fukui, Doi, 1998; Kahar et al., 2004). $\beta$-окисление жирных кислот приводит к увеличению концентрации ацетил-СоА, который является основным метаболитом в клетке и для построения органических молекул (вклю- чая ПГА), и для энергетических нужд синтеза через цикл трикарбоновых кислот. В настоящее время применение жирных кислот и липидов для микробного производства ценных продуктов набирает популярность, так как синтез веществ, подобных ПГА, более эффективен при использовании микроорганизмами таких субстратов из-за более высокого удельного молярного содержания в них углерода (Kahar et al., 2004; Riedel et al., 2012; Tsuge et al., 2013). Показано, что экономический коэффициент по ПГА при росте на глюкозе составлял всего лишь 0,32-0,48 г ПГА/г используемой глюкозы (Yamane, 1992), тогда как на соевом масле - от 0,72 до 0,76 г ПГА/г масла (Fukui, Doi, 1998; Kahar et al., 2004). Использование в качестве источника углерода для продукции ПГА олеиновой кислоты как одной из широко распространенных ЖК и частого компонента триацилглицеринов природных масел показано для Aeromonas hydrophila (Chen et al., 2001), Ralstonia eutropha (Marangoni et al., 2000; Grigull et al., 2008), Bacillus cereus (Masood et al., 2017).

Целью данной работы было исследование влияния различных концентраций олеиновой кислоты на рост бактерий Cupriavidus necator B-10646, синтез полимера и его характеристики.

\section{Материалы и методы}

В работе использовали штамм водородокисляющих бактерий C. necator B-10646, депонированный во Всероссийской коллекции промышленных микроорганизмов. Бак- 
терии выращивали в течение 48 ч в жидкой солевой среде в стеклянных колбах объемом 1 л при коэффициенте заполнения 0,5 с использованием термостатируемого шейкераинкубатора Innova ${ }^{\circledR}$ серии 44 (New Brunswick Scientific, США) при $30{ }^{\circ} \mathrm{C}$ и 200 об/мин. Для выращивания бактерий использовали среду Шлегеля (Schlegel et al., 1961): $\mathrm{Na}_{2} \mathrm{HPO}_{4} \times \mathrm{H}_{2} \mathrm{O}-$ 9,$1 ; \quad \mathrm{KH}_{2} \mathrm{PO}_{4}-1,5 ; \quad \mathrm{MgSO}_{4} \times \mathrm{H}_{2} \mathrm{O}-0,2 ;$ $\mathrm{Fe}_{3} \mathrm{C}_{6} \mathrm{H}_{5} \mathrm{O}_{7} \times 7 \mathrm{H}_{2} \mathrm{O}-0,025 ; \mathrm{NH}_{4} \mathrm{Cl}-1$ (г/л). Микроэлементы вводили по прописи Хоагланда из расчета 3 мл стандартного раствора на 1 л среды. Стандартный раствор содержит: $\mathrm{H}_{3} \mathrm{BO}_{3}-0,288 ; \mathrm{CoCl}_{2} \times 6 \mathrm{H}_{2} \mathrm{O}-0,030$; $\mathrm{CuSO}_{4} \times 5 \mathrm{H}_{2} \mathrm{O}-0,08 ; \mathrm{MnCl}_{2} \times 4 \mathrm{H}_{2} \mathrm{O}-0,008 ;$ $\mathrm{ZnSO}_{4} \times 7 \mathrm{H}_{2} \mathrm{O}-0,176 ; \mathrm{NaMoO}_{4} \times 2 \mathrm{H}_{2} \mathrm{O}-0,050$; $\mathrm{NiCl}_{2}-0,008$ (г/л). В качестве углеродного субстрата взята олеиновая кислота (АО «ЭКОС-1», Россия; степень чистоты 98-99 \%) в концентрациях 5-50 г/л.

Расчет экономического коэффициента по биомассе проводили по формуле

$$
\mathrm{Y}=\left(\mathrm{X}-\mathrm{X}_{0}\right) /\left(\mathrm{S}_{0}-\mathrm{S}\right)
$$

где $\mathrm{X}$ и $\mathrm{X}_{0}$ - концентрация биомассы в конце и в начале эксперимента соответственно; $\mathrm{S}$ и $\mathrm{S}_{0}$ - концентрация субстрата в культуре в конце и в начале эксперимента соответственно.

Расчет экономического коэффициента по полимеру проводили по формуле:

$$
\mathrm{Y}=\left(\mathrm{P}-\mathrm{P}_{0}\right) /\left(\mathrm{S}_{0}-\mathrm{S}\right),
$$

где $\mathrm{P}$ и $\mathrm{P}_{0}$ - концентрация полимера в конце и в начале эксперимента соответственно, $\mathrm{S}$ и $\mathrm{S}_{0}$ - концентрация субстрата в культуре в конце и в начале эксперимента соответственно.

Концентрацию биомассы бактерий регистрировали по весу сухого вещества и оптической плотности культуры на колориметре КФК-2МП (Россия) при длине $\lambda=440$ нм. Содержание олеиновой кислоты в среде определяли после экстракции ее гексаном на хромато-масс-спектрометре Agilent Technologies 7890A (США). Содержание и состав полимера определяли хроматографией метиловых эфиров жирных кислот с применением хромато-масс-спектрометра Agilent Technologies 7890A (СШA) (Volova et al., 2002). Условия хроматографии: газноситель - гелий, скорость 1,2 мл/мин; колонка капиллярная DB-35MS, длина 30 м, диаметр 0,25 мм; начальная температура $55^{\circ} \mathrm{C}$, подъем температуры до $310{ }^{\circ} \mathrm{C}$ со скоростью $10{ }^{\circ} \mathrm{C} /$ мин. Молекулярную массу и молекулярно-массовое распределение полимера исследовали с использованием гельпроникающей хроматографии (хроматограф Agilent Technologies 1260 Infinity (США)) относительно полистироловых стандартов (Fluka, Швейцария, Германия). Находили средневесовую $\left(\mathrm{M}_{\mathrm{B}}\right)$ и среднечисловую $\left(\mathrm{M}_{4}\right)$ молекулярную массу, а также полидисперсность (ПД $=\mathrm{M}_{\mathrm{z}} / \mathrm{M}_{\mathrm{q}}$ ). Подробное описание метода оценки молекулярно-массового распределения полимера приведено в работе (Volova et al., 2014). Термический анализ проводили с помощью дифференциально-сканирующего калориметра DSC-1 (Mettler Toledo,

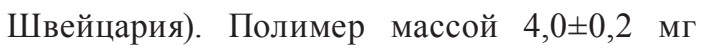
помещали в алюминиевые тигли и нагревали со скоростью $5{ }^{\circ} \mathrm{C}$ в минуту. Температуру плавления $\left(\mathrm{T}_{\text {пл }}\right)$ и термической деградации $\left(\mathrm{T}_{\text {дегр }}\right)$ определяли по экзотермическим пикам на термограммах с использованием программного обеспечения «StarE» (Mettler Toledo, Швейцария).

Эксперименты проведены в трех повторностях. Приведены среднеарифметические значения и их стандартные отклонения. Для оценки достоверности влияния различных концентраций олеиновой кислоты на концентрацию биомассы и содержание полимера 
выполнен однофакторный дисперсионный анализ при уровне значимости $\alpha=0,05$.

\section{Результаты и обсуждение}

Исследовано влияние различных концентраций олеиновой кислоты (5-50 г/л) на рост бактерий и содержание полимера, его состав и молекулярный вес. Максимальная концентрация биомассы 6,4-6,7 г/л получена при концентрациях олеиновой кислоты в среде 10-20 г/л. Дальнейшее увеличение концентрации олеиновой кислоты привело к снижению показателей урожайности биомассы (рис. 1). Максимальное содержание полимера (64-71 \% от веса сухой биомассы) также получено при невысоких концентрациях олеиновой кислоты (10-25 г/л) (рис. 2). Дисперсионный анализ показал, что влияние концентрации олеиновой кислоты на величину урожайности по биомассе и содержанию полимера статистически достоверно $\left(n=24, F_{\text {биомасса }}=531, F_{\text {полимер }}=507\right.$, $\alpha=0,05)$. Низкое содержание биомассы (3,5 г/л) и полимера (48 \% от веса сухой биомассы) при концентрации олеиновой кислоты 5 г/л, по всей видимости, связано с полной утилизацией данного субстрата на более ранних стадиях культивирования, что подтверждается отсутствием олеиновой кислоты в культуральной среде в конце культивирования (табл. 1). Следует отметить, что практически вся кислота была утилизирована бактериями за 48 ч только при исходной концентрации олеиновой кислоты 5 и 10 г/л, тогда как при более высоких начальных концентрациях (25-50 г/л) в среде осталось много неиспользованной олеиновой кислоты.

При культивировании C. necator B-10646 на олеиновой кислоте экономический коэффициент по биомассе (Y) составлял 0,640,72 г биомассы/г используемого субстрата (табл. 1), что практически в 2 раза выше, чем при культивировании на сахарах (Kahar et al., 2004; Riedel et al., 2012; Tsuge et al., 2013), и согласуется с ранее полученными результатами других авторов (Yamane, 1992; Akiyama et al., 2003).

Ранее показано, что исследуемый штамм C. necator B-10646 при росте на сахарах (фрук-

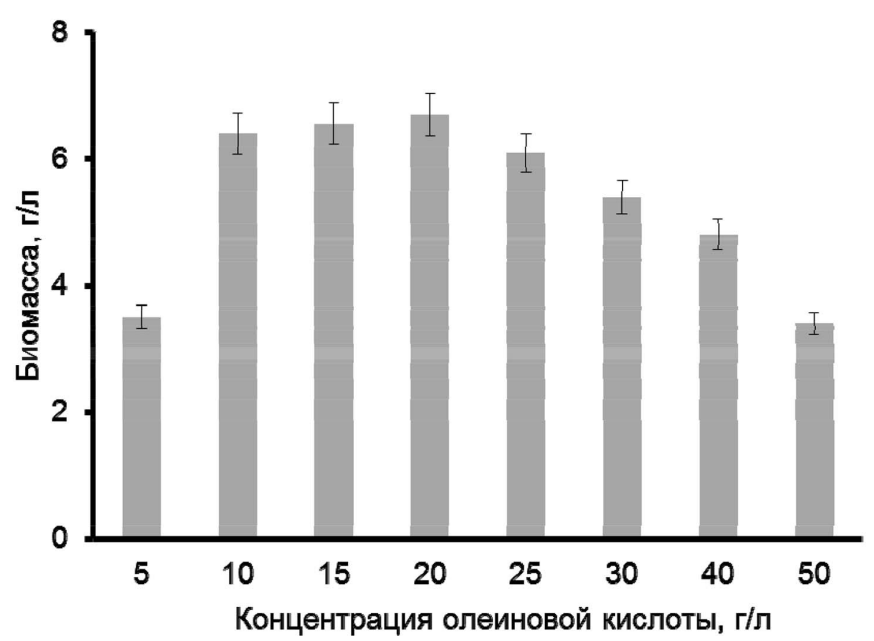

Рис. 1. Влияние концентрации олеиновой кислоты в среде на рост бактерий Cupriavidus necator B-10646

Fig. 1. The effect of the concentration of oleic acid in the medium on the growth of bacterium Cupriavidus necator B-10646 


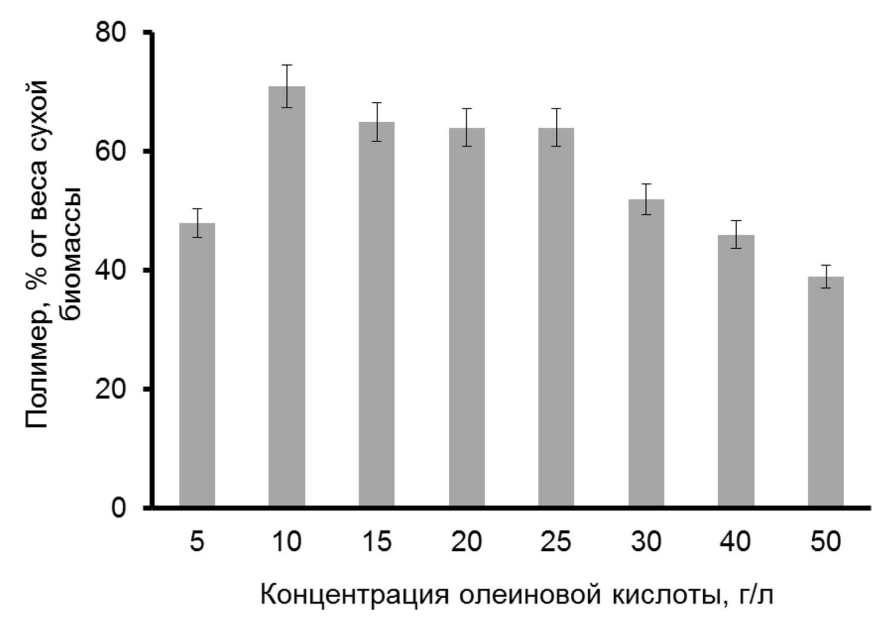

Рис. 2. Содержание полимера в клетках бактерий Cupriavidus necator B-10646 в конце культивирования (48 ч) при различных концентрациях олеиновой кислоты в среде

Fig. 2. Polymer content in the cells of Cupriavidus necator B-10646 at the end of cultivation (48 h) at various concentrations of oleic acid in the medium

Таблица 1. Показатели культуры бактерий Cupriavidus necator B-10646, выращиваемых при различных концентрациях олеиновой кислоты в среде

Table 1. The culture parameters of Cupriavidus necator B-10646 grown at different concentrations of oleic acid in the medium

\begin{tabular}{|c|c|c|c|c|c|c|c|c|c|}
\hline \multirow{2}{*}{$\begin{array}{c}\text { Концентрация } \\
\text { олеиновой } \\
\text { кислоты в } \\
\text { среде в начале } \\
\text { культивиро- } \\
\text { вания, г/л }\end{array}$} & \multicolumn{3}{|c|}{$\begin{array}{c}\text { Состав полимера, } \\
\text { мол . \% }\end{array}$} & \multirow{2}{*}{$\begin{array}{l}\mathrm{M}_{\mathrm{B}} \\
\text { кДа }\end{array}$} & \multirow{2}{*}{$\begin{array}{l}\mathrm{M}_{\mathrm{u}} \\
\text { кДа }\end{array}$} & \multirow{2}{*}{ ПД } & \multirow{2}{*}{$\begin{array}{c}\text { Содержание } \\
\text { олеиновой } \\
\text { кислоты } \\
\text { в конце } \\
\text { культивиро- } \\
\text { вания, г/л }\end{array}$} & \multirow{2}{*}{$\begin{array}{c}\text { Y, } \\
\text { г биомассы/ } \\
\text { г субстрата }\end{array}$} & \multirow{2}{*}{$\begin{array}{c}\mathrm{Y}, \\
\text { г полимера/ } \\
\text { г субстрата }\end{array}$} \\
\hline & ЗГБ & ЗГВ & $3 Г \Gamma$ & & & & & & \\
\hline 5 & 98,5 & 1,2 & 0,3 & 803 & 292 & 2,8 & - & 0,70 & 0,34 \\
\hline 10 & 98,7 & 0,9 & 0,4 & 642 & 222 & 2,9 & 0,6 & 0,68 & 0,48 \\
\hline 15 & 98,9 & 1,0 & 0,2 & 617 & 217 & 2,8 & 5,9 & 0,72 & 0,47 \\
\hline 20 & 98,8 & 1,0 & 0,2 & 604 & 199 & 3,0 & 10,1 & 0,68 & 0,43 \\
\hline 25 & 99,1 & 0,7 & 0,2 & 595 & 190 & 3,1 & 15,5 & 0,64 & 0,41 \\
\hline 30 & 98,9 & 1,1 & - & 485 & 109 & 4,4 & 22,3 & 0,70 & 0,36 \\
\hline 40 & 98,6 & 1,3 & 0,1 & 423 & 104 & 4,1 & 33,3 & 0,72 & 0,33 \\
\hline 50 & 98,0 & 1,7 & 0,3 & 381 & 94 & 4,1 & 45,2 & 0,71 & 0,28 \\
\hline
\end{tabular}

Примечание: -- отсутствует.

тоза, глюкоза) синтезирует гомополимер поли(3-гидроксибутират) (Zhila et al., 2015). В составе полимера, синтезируемого бактериями при росте на олеиновой кислоте, помимо 3-гидроксибутирата, являющегося доминирующим мономером (более 98 мол. \%), иден- тифицированы включения 3-гидроксивалерата (0,7-1,7 мол. \%) и 3-гидроксигексаноата (0,1-0,4 мол. \%). Однако процентное содержание мономеров ЗГВ и ЗГГ практически не зависело от концентрации олеиновой кислоты в среде (табл. 1). Появление 3-гидроксивале- 
рата и 3-гидроксигексаноата в составе полимера также наблюдали при культивировании Alcaligenes sp. NCIM No 5085 на олеиновой кислоте (Srivastava, Tripathi, 2013). Кроме того, изменение состава полимера у Bacillus cereus FA11 при замене углеводного субстрата на оливковое масло показано в работе (Masood et al., 2017).

Помимо общего выхода, исследованы состав и молекулярно-массовые характеристики ПГА, синтезируемых бактериями C. necator B-10646 (табл. 1). Показано, что с увеличением концентрации олеиновой кислоты происходило снижение как средневесовой, так и среднечисловой молекулярной массы на фоне увеличения полидисперсности. Известно, что молекулярная масса ПГА зависит от нескольких факторов: типа ПГА-синтазы, доступности мономеров для синтеза ПГА, присутствия ферментов, которые деполимеризуют ПГА, и уровня экспрессии ПГА синтазы (Rehm, 2003). Синтез ПГА с низкими значениями $\mathrm{M}_{\mathrm{B}}$ происходит при высокой концентрации в клетках активной ПГА-синтазы и/или высокой экспрессии гена, кодирующего этот фермент (Sim et al., 1997). Наличие других мономеров в сополимере может также приводить к значительному снижению его молекулярной массы. Снижение молекулярной массы полимера и возрастание его полидисперсности при увеличении концентрации олеиновой кислоты, как предположили Jurasek et al. (2004) и Tomizawa et al. (2010), были связаны со снижением скорости работы ПГА-синтазы и/или увеличением скорости реакции переноса цепи. Следует отметить, что полимер, синтезируемый на фруктозе исследуемым штаммом C. necator B-10646, характеризовался более высокой молекулярной массой (Volova et al., 2017). Снижение молекулярной массы полимера у Aeromonas caviae $505 \mathrm{E} / \mathrm{K} / \mathrm{P}$ при росте на соевом масле по сравнению с фруктозой показано в работе Tsuge et al. (2007). Более низкие значения молекулярной массы получены и для Cupriavidus necator Н16 при выращивании бактерий на пальмовом масле по сравнению с фруктозой (Arikawa et al., 2016).

ПГА, синтезируемые C. necator B-10646 при росте на олеиновой кислоте, характеризуются более низкой температурой плавления $\left(\mathrm{T}_{\text {пл }}\right)$ по сравнению с полимером, полученным при использовании фруктозы в качестве источника углерода (табл. 2). Возможно, это

Таблица 2. Температурные характеристики полимеров, полученных при выращивании бактерий на олеиновой кислоте

Table 2. Temperature characteristics of polymers synthesized by bacterial cells grown on oleic acid

\begin{tabular}{|c|c|c|c|c|c|c|}
\hline \multirow{2}{*}{$\begin{array}{c}\text { Концентрация } \\
\text { олеиновой кислоты } \\
\text { в среде, г/л }\end{array}$} & \multicolumn{3}{|c|}{ Состав полимера, мол. \% } & \multirow[b]{2}{*}{$\mathrm{T}_{\text {плл }},{ }^{\circ} \mathrm{C}$} & \multirow[b]{2}{*}{$\mathrm{T}_{\text {дегр }},{ }^{\circ} \mathrm{C}$} & \multirow[b]{2}{*}{ Ссылка } \\
\hline & ЗГБ & ЗГВ & ЗГГ & & & \\
\hline 10 & 98,7 & 0,9 & 0,4 & 162 & 288 & Это исследование \\
\hline 30 & 98,9 & 1,1 & - & 168 & 294 & Это исследование \\
\hline 50 & 98,0 & 1,7 & 0,3 & 169 & 291 & Это исследование \\
\hline 0 & 100 & - & - & 178 & 295 & Volova et al., 2017 \\
\hline 0 & 100 & - & - & 173 & н.д. & Grigull et al., 2008 \\
\hline 1,5 & 100 & - & - & 171 & н.д. & Grigull et al., 2008 \\
\hline 3,0 & 100 & - & - & 149,162 & н.д. & Grigull et al., 2008 \\
\hline
\end{tabular}

Примечание: - - отсутствует, н.д. - нет данных. 
связано с имеющимися в составе ПГА в небольших количествах мономерами $3 Г В$ и $3 Г Г$, наличие которых в полимере, как известно, сопровождается снижением $\mathrm{T}_{\text {пл }}$ (Murugan et al., 2017; Volova et al., 2013). Однако в работе Grigull et al. (2008) показано снижение $\mathrm{T}_{\text {пл }}$ гомополимера П(ЗГБ), синтезированного в присутствии олеиновой кислоты в концентрации 3 г/л, по сравнению с П(ЗГБ), полученным при более низких концентрациях олеиновой кислоты или при ее отсутствии в среде (табл. 2).

\section{Заключение}

Исследован рост C. necator B-10646 и синтез полимера при выращивании бактерий на среде, содержащей в качестве единственного источника углерода олеиновую кислоту в концентрациях 5-50 г/л. Максимальные величины урожайности по биомассе и содер- жанию полимера получены при исходных концентрациях олеиновой кислоты 10-20 г/л и минимальных остаточных концентрациях субстрата (0,6-10,1 г/л). Установлено, что полимер, синтезируемый бактериями в присутствии олеиновой кислоты, не является гомополимером П(ЗГБ) - в его составе помимо основного мономера ЗГБ входят мономеры

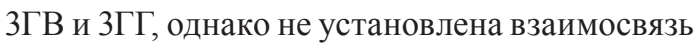
между концентрацией олеиновой кислоты и

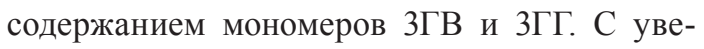
личением концентрации олеиновой кислоты происходило снижение средневесовой и среднечисловой молекулярной массы полимера. Таким образом, культивирование бактерий с целью получения полимера при использовании в качестве субстрата олеиновой кислоты лучше проводить при относительно низких ее концентрациях.

\section{Благодарности / Acknowledgements}

Исследование выполнено при финансовой поддержке Российского фонда фундаментальных исследований, Правительства Красноярского края, Красноярского краевого фонда поддержки научной и научно-технической деятельности в рамках научного проекта № 17-44240775 и гос. задания № FSRZ-2020-0006.

This study was financially supported by the Russian Foundation for Basic Research and the Government of the Krasnoyarsk Territory, the Krasnoyarsk Regional Fund for the Support of Scientific and Scientific-Technical Activities (Project No. 17-44-240775) and State Assignment № FSRZ-20200006.

\section{Список литературы / References}

Akiyama M., Tsuge T., Doi Y. (2003) Environmental life cycle comparison of polyhydroxyalkanoates produced from renewable carbon resources by bacterial fermentation. Polymer Degradation and Stability, 80(1): 183-194

Arikawa H., Sato S., Fujiki T., Matsumoto K. (2016) A study on the relation between poly(3hydroxybutyrate) depolymerases or oligomer hydrolases and molecular weight of polyhydroxyalkanoates accumulating in Cupriavidus necator H16. Journal of Biotechnology, 227: 94-102

Chen Y.G., Yang H.Z., Zhou Q., Chen J., Gu G.W. (2001) Cleaner recovery of poly(3-hydroxybutyric acid) synthesized in Alcaligenes eutrophus. Process Biochemistry, 36(6): 501-506

Fukui T., Doi Y. (1998) Efficient production of polyhydroxyalkanoates from plant oils by Alcaligenes eutrophus and its recombinant strain. Applied Microbiology and Biotechnology, 49(3): 333-336 
Grigull V.H., da Silva D.D., Garcia M.C.F., Furlan S.A., Pezzin A.P.T., Schneider A.L.S., Aragão G.F. (2008) Production and characterization of poly(3-hydroxybutyrate) from oleic acid by Ralstonia eutropha. Food Technology and Biotechnology, 46(2): 223-228

Jurasek L., Marchessault R.H. (2004) Polyhydroxyalkanoate (PHA) granule formation in Ralstonia eutropha cells: a computer simulation. Applied Microbiology and Biotechnology, 64(5): 611-617

Kahar P., Tsuge T., Taguchi K., Doi Y. (2004) High yield production of polyhydroxyalkanoates from soybean oil by Ralstonia eutropha and its recombinant strain. Polymer Degradation and Stability, 83(1): 79-86

Kim B.S. (2000) Production of poly(3-hydroxybutyrate) from inexpensive substrates. Enzyme and Microbial Technology, 27(10): 774-777

Lee S.Y., Choi J.I. (1998) Effect of fermentation performance on the economics of poly(3hydroxybutyrate) production by Alcaligenes latus. Polymer Degradation and Stability, 59(1-3): 387-393

Marangoni C., Furigo A.Jr., de Aragão G.M.F. (2000) Oleic acid improves poly(3-hydroxybutyrateco-3-hydroxyvalerate) production by Ralstonia eutropha in inverted sugar and propionic acid. Biotechnology Letteres, 22(20): 1635-1638

Masood F., Abdul-Salam M., Yasin T., Hameed A. (2017) Effect of glucose and olive oil as potential carbon sources on production of PHAs copolymer and tercopolymer by Bacillus cereus FA11. 3 Biotech, 7: 87

Murugan P., Gan C.-Y., Sudesh K. (2017) Biosynthesis of P(3HB-co-3HHx) with improved molecular weights from a mixture of palm olein and fructose by Cupriavidus necator Re2058/pCB113. International Journal of Biological Macromolecules, 102: 1112-1119

Rehm B.H.A. (2003) Polyester synthases: natural catalysts for plastics. Biochemical Journal, 376(1): 15-33

Riedel S.L., Bader J., Brigham C.J., Budde C.F., Yusof Z.A.M., Rha C., Sinskey A.J. (2012) Production of poly(3-hydroxybutyrate-co-3-hydroxyhexanoate) by Ralstonia eutropha in high cell density palm oil fermentations. Biotechnology and Bioengineering, 109(1): 74-83

Schlegel H.G., Kaltwasser H., Gottschalk G. (1961) A submersion method for culture of hydrogenoxidizing bacteria: growth physiological studies. Archiv für Mikrobiologie, 38: 209-222 (in German)

Sim S.J., Snell K.D., Hogan S.A., Stubbe J., Rha C.K., Sinskey A.J. (1997) PHA synthase activity controls the molecular weight and polydispersity of polyhydroxybutyrate in vivo. Nature Biotechnology, 15(1): 63-67

Srivastava S.K., Tripathi A.D. (2013) Effect of saturated and unsaturated fatty acid supplementation on bio-plastic production under submerged fermentation. 3Biotech, 3(5): 389-397

Tomizawa S., Saito Y., Hyakutake M., Nakamura Y., Abe H., Tsuge T. (2010) Chain transfer reaction catalyzed by various polyhydroxyalkanoate synthases with poly(ethylene glycol) as an exogenous chain transfer agent. Applied Microbiology and Biotechnology, 87(4): 1427-1435

Tsuge T., Watanabe S., Sato S., Hiraishi T., Abe H., Doi Y., Taguchi S. (2007) Variation in copolymer composition and molecular weight of polyhydroxyalkanoate generated by saturation mutagenesis of Aeromonas caviae PHA synthase. Macromolecular Bioscience, 7(6): 846-854

Tsuge T., Ko T., Tago M., Abe H. (2013) Effect of glycerol and its analogs on polyhydroxyalkanoate biosynthesis by recombinant Ralstonia eutropha: a quantitative structure-activity relationship study of chain transfer agents. Polymer Degradation and Stability, 98(9): 1586-1590 
Volova T.G., Kalacheva G.S., Altukhova O.V. (2002) Autotrophic synthesis of polyhydroxyalkanoates by the bacteria Ralstonia eutropha in the presence of carbon monoxide. Applied Microbiology and Biotechnology, 58(5): 675-678

Volova T.G., Zhila N.O., Shishatskaya E.I., Mironov P.V., Vasil'ev A.D., Sukovatyi A.G., Sinskey A.J. (2013) The physicochemical properties of polyhydroxyalkanoates with different chemical structures. Polymer Science, Series A, 55(7): 427-437

Volova T., Kiselev E., Vinogradova O., Nikolaeva E., Chistyakov A., Sukovatiy A., Shishatskaya E. (2014) A glucose-utilizing strain, Cupriavidus euthrophus B-10646: growth kinetics, characterization and synthesis of multicomponent PHAs. PLoS One, 9(2): e87551

Volova T.G., Vinogradova O.N., Zhila N.O., Kiselev E.G., Peterson I.V., Vasil'ev A.D., Sykovatyi A.G., Shishatskaya E.I. (2017) Physicochemical properties of multicomponent polyhydroxyalkanoates: novel aspects. Polymer Science, Series A, 59(1): 98-106

Yamane T. (1992) Cultivation engineering of microbial bioplastics production. FEMS Microbiology Reviews, 103(2-4): 257-264

Zhila N., Kalacheva G., Volova T. (2015) Fatty acid composition and polyhydroxyalkanoates production by Cupriavidus eutrophus B-10646 cells grown on different carbon sources. Process Biochemistry, 50(10): 69-78 